INRA Prod. Anim.,

2010, 23 (2), 193-204

\title{
Microbiologie de l'œuf et des ovoproduits
}

INRA, UMR1253 Microbiologie, F-35000 Rennes, France Agrocampus Ouest, Microbiologie, F-35000 Rennes, France

Courriel : florence.baron@agrocampus-ouest.fr

La garantie sanitaire est une préoccupation majeure de la filière œufs et ovoproduits. Bien connaitre les microorganismes contaminants, leur origine, leur comportement dans les différentes parties de l'œuf et dans les ovoproduits, ainsi que l'influence des pratiques d'élevage et des opérations de transformation sur la contamination, permet d'envisager des moyens de la maîtriser.

Selon l'Institut de Veille Sanitaire français (InVS), les microorganismes pathogènes responsables de ToxiInfections Alimentaires Collectives (TIAC), en France entre 1996 et 2005, pour lesquels les «œufs et produits à base d'œufs» ont été incriminés sont Salmonella $(85,9 \%)$, Staphylococcus aureus (7\%), Clostridium perfringens $(2,3 \%)$ ou d'autres agents $(4,4 \%)$ (Delmas et al 2006). Les données les plus récentes (2008) mises en ligne sur le site de l'InVS font état de pourcentages similaires. En Europe, environ $90 \%$ des salmonelloses humaines dues à la consommation d'œufs ou de produits à base d'œufs contaminés sont liées à $S$. Enteritidis (Efsa 2007). $S$. Enteritidis reste le sérotype prédominant dans les toxi-infections alimentaires dues à Salmonella en 2007 (Efsa 2009). Il représente $60,2 \%$ des toxi-infections collectives confirmées de Salmonella, $66,6 \%$ des cas isolés de Salmonella, $77,8 \%$ des hospitalisations et $100 \%$ des accidents mortels en 2007. Le risque de contamination par les microorganismes, et notamment par Salmonella, est donc une préoccupation majeure de la filière œufs et ovoproduits. Nous nous intéresserons aux microorganismes contaminant les œufs et les ovoproduits, à leur origine, à leur comportement dans les différentes parties de l'œuf et dans les ovoproduits, à l'influence des pratiques d'élevage et des opérations de transformation sur la contamination et aux moyens de la maîtriser.

\section{1 / Microbiologie de l'œuf}

Au moment de la ponte, le contenu des œufs provenant d'élevages sains est en général stérile. Il peut toutefois être contaminé par une flore diversifiée contenant des microorganismes d'altération et parfois pathogènes. L'œuf peut donc véhiculer et transmettre des microorganismes à l'origine de toxi-infections alimentaires chez l'Homme : c'est notamment le cas de Salmonella.

L'œuf dispose cependant d'un arsenal remarquable de défenses destinées à préserver l'embryon de toutes invasions microbiennes au cours de son développement. Ces défenses peuvent être affectées par les conditions de collecte, de conditionnement et de stockage des œufs.

Nous nous intéresserons à l'origine des contaminations de l'œuf, à la compréhension de ses mécanismes de défense anti-microbienne. Enfin, les mesures permettant de limiter la présence et le développement des microorganismes dans l'œuf seront discutées, au niveau de l'élevage, du stockage et du conditionnement.

\section{1 / Contamination verticale}

Au moment de la ponte, le contenu de l'œuf provenant d'un élevage sain est en général stérile. Cependant, l'œuf peut être contaminé par voie verticale, lors de sa formation dans l'oviducte. La contamination verticale concerne principalement Salmonella, mais des études évoquent aussi l'implication de bactéries de l'espèce Campylobacter jejuni et du virus de l'Influenza aviaire.

Dans le cas de Salmonella, la contamination de l'œuf peut se produire lors de sa formation, si les poules présentent une infection des ovaires ou de l'oviducte. Il n'existe pas de relation directe entre portage fécal et présence de
Salmonella dans le contenu de l'œuf (Gast et Beard 1990). Salmonella peut en effet être isolée du tractus reproducteur pour lequel elle semble avoir un fort tropisme même en l'absence de contamination intestinale (De Buck et al 2004).

L'inoculation artificielle (par voie orale, intraveineuse ou péritonéale) par Salmonella Enteritidis a été pratiquée par différentes équipes et a montré qu'elle conduit effectivement à la contamination des œufs. Cette transmission ne se fait cependant qu'à une faible fréquence, de manière intermittente et pour de forts taux d'inoculation (de l'ordre de $10^{8}$ à $10^{9}$ cellules par poule). Selon les auteurs, les taux d'œufs contaminés varient de 0 à $8,1 \%$, avec des faibles niveaux de contamination (entre 1 et 10 cellules/mL) (Keller et al 1995, Gast et al 2002). La contamination verticale a aussi été montrée pour Salmonella Heidelberg (Gast et al 2007) et Salmonella Pullorum (Wigley et al 2001) mais jamais pour Salmonella Typhimurium (Keller et al 1995, Reiber et al 1995), Salmonella Infantis et Salmonella Hadar, (Okamura et al 2001) même si ces espèces peuvent être détectées sur les œufs après la ponte (voie horizontale).

Des études menées sur des poules expérimentalement infectées ont montré que la contamination pouvait apparaître à toutes les étapes de la formation de l'œuf. Ainsi, certains auteurs ont observé une fréquence de contamination du blanc supérieure à celle du jaune et liée à la contamination du magnum, lieu du dépôt de l'albumen (Gast et Beard 1990, Shivaprasad et al 1990, Keller et al 1995). D'autres auteurs impliquent 
au contraire l'ovaire, sachant qu'ils observent une contamination du jaune ou de la membrane vitelline (Gast et Holt 2000a). Dans tous les cas, il semble que Salmonella soit plus fréquemment isolée du contenu de l'œuf que de la coquille, ce qui suggère une contamination de l'ovaire ou de la partie supérieure de l'oviducte (magnum) et une contamination de l'œuf en formation avant le dépôt de la coquille (Gast et Beard 1990, Susuki 1994).

Keller et al (1995) observent une différence entre les taux de contamination des tissus de poules de lignée Leghorn par rapport aux poules de lignée ISA Brown, ces dernières présentant les taux les plus élevés pour la souche utilisée. L'âge de la poule est également important: la résistance à la salmonellose chez les poules augmente en général avec l'âge, sans doute en relation avec le développement d'une flore intestinale mature et d'un système immunitaire efficace à l'âge adulte (Susuki 1994). Entre 27 et 60 semaines, la contamination de la coquille serait cependant indépendante de l'âge (Protais et al 2003).

Dans le cas de Campylobacter jejuni, espèce fréquemment isolée chez la poule et responsable d'un grand nombre de diarrhées infantiles chez l'Homme, Sahin et al (2003) ont montré des cas de contamination verticale, même si cet évènement reste rare et peu impliqué dans la contamination des œufs.

Swayne et Beck (2004) ont pu mettre en évidence une contamination verticale par le virus de l'Influenza aviaire de type $\mathrm{A}$, qui provoque une virose chez plusieurs espèces d'oiseaux dont les poules. Cependant, ce virus ne constitue pas un risque alimentaire pour l'Homme et, en cas d'épidémie, la mise en place de mesures efficaces est prévue par les autorités compétentes.

Pour conclure, la contamination verticale de l'œuf est possible mais elle reste faible, sporadique et beaucoup moins importante que la contamination des œufs après la ponte.

\section{2 / Contamination horizontale}

La contamination horizontale, beaucoup plus fréquente que la contamination verticale, correspond à la contamination de la surface de la coquille des œufs. Elle intervient après la ponte, par contact avec les microorganismes des fientes, de l'environnement d'élevage ou, en aval, du centre de conditionnement.

Selon les études, les niveaux de contamination de la coquille en flore mésophile aérobie varient de $10^{3,8}$ à $10^{6,3}$ ufc/œuf, avec des niveaux moyens de l'ordre de 104,5 ufc/œuf (Moats 1980, Jones et al 2004, Musgrove et al 2005, De Reu et al 2006a). En ce qui concerne les types de contamination, Moats (1980) a isolé, par des méthodes de bactériologie classiques, des bactéries à coloration de Gram positive des genres Streptococcus, Aerococcus, Micrococcus et Staphylococcus ainsi que des E. coli. De Reu et al (2006a) ont identifié les espèces majoritaires présentes sur les coquilles par séquençage de l'ADN $16 \mathrm{~S}$ après isolement des colonies sur un milieu nutritif non sélectif. Ils observent une prédominance d'E. coli $\left(5,5.10^{4}\right.$ ufc/œuf) et du genre Staphylococcus $\left(4,3.10^{4}\right.$ ufc/œuf), S. linens et $S$. equorum étant les espèces les plus représentées.

Les facteurs influençant les niveaux et les types de contamination des œufs sont liés à l'état sanitaire de la poulette, de la poule et de l'environnement d'élevage. Les bactéries et notamment Salmonella peuvent survivre dans l'environnement d'élevage et favoriser la contamination de l'ensemble de la bande, voire la contamination entre deux bandes différentes. Les poux, insectes, rongeurs sont des réservoirs et vecteurs potentiels de contamination. Les autres sources de contamination sont l'aliment des poules et la poussière dont le taux varie selon l'activité et le comportement des poules (notamment le comportement de ponte), l'utilisation de cages et leur type (cages conventionnelles ou aménagées), l'utilisation de volières, le matériel, les litières et les aliments utilisés (De Reu et al 2005). La contamination dépend aussi de la saison, une contamination moindre étant observée pendant la période hivernale (De Reu et al 2005, Wales et al 2007).

La contamination pendant le transport ou le conditionnement en centre de tri peut se faire soit par l'environnement, soit directement par transmission d'œuf à œuf, un fort pourcentage d'œufs fêlés ou «coulants» augmentant le risque. Ainsi le conditionnement est une opération qui n'est pas à négliger en termes de contamination (Davies et Breslin 2003).

En ce qui concerne $S$. Enteritidis, les poules hébergeant durablement ce sérotype dans leur tube digestif en l'absence de symptômes (portage asymptomatique), elles peuvent excréter une quantité importante de bactéries dans la matière fécale. Cette excrétion est probablement à l'origine de la dissémination des bactéries chez les animaux sains et dans l'environnement d'élevage.

La maîtrise des facteurs influençant la contamination de la coquille est donc essentielle pour éviter la dissémination des microorganismes. En ce qui concerne Salmonella, on peut noter que seules $17 \%$ des bandes étaient positives en France en 2005 (Efsa 2007) et qu'au niveau européen, les taux varient de 0 à $79,5 \%$. Néanmoins, le pourcentage d'œufs frais contaminés reste souvent inférieur à $1 \%$.

\section{3 / Pénétration des microorga- nismes dans l'œuf}

Même si la surface de l'œuf est contaminée, la cuticule, la coquille et les membranes coquillières sont autant de barrières qui s'opposent à la pénétration des microorganismes, de la surface vers le contenu de l'œuf.

La cuticule est un film mucoprotéique imperméable à l'eau et aux microorganismes. L'efficacité de cette enveloppe protectrice est cependant limitée, puisqu'elle se craquèle rapidement dans le temps et lors de la manipulation des œufs (Vadehra et al 1970, Tung et al 1979, De Reu et al 2006b).

La coquille constitue une couche protéique calcifiée qui représente une barrière physique peu efficace en raison du passage possible des microorganismes à travers les pores qui la traversent. Elle contient cependant du lysozyme et de l'ovotransferrine qui peuvent jouer un rôle dans la protection contre la pénétration (Hincke et al 2000, Gautron et al 2001).

Les membranes coquillières, externe et interne, sont quant à elles des filtres anti-bactériens efficaces constitués de fibres glycoprotéiques organisées en réseaux, de lysozyme, de $\beta-\mathrm{N}$-acétylglucosaminidase et d'ovotransferrine (Hincke et al 2000, Gautron et al 2001, Ahlborn et Sheldon 2005).

Différents auteurs ont étudié les facteurs favorisant la pénétration des microorganismes dans les œufs. Les méthodes utilisées aboutissent à des conclusions parfois contradictoires et les résultats des études menées in vitro sont à considérer avec précaution, les taux d'inoculation des coquilles étant en général plus élevés que ceux observés naturellement. Il ressort cependant de ces études que le poids de l'œuf, l'épaisseur de la coquille (Messens et al 2005 et 2007), le nombre de pores, la qualité de la cuticule (Messens et al 2005) et la condensation (Ernst et Fuqua 1998, Allen et Griffiths 2001) apparaissent peu corrélés au taux de pénétration des microorganismes. En effet, même si la condensation, générée par une humidité importante associée à des variations de température, favorise la pénétration par rétraction du contenu de l'œuf et absorption de l'eau et des microorganismes 
présents sur la coquille (Miyamoto et al 1998, De Reu et al 2005), les conditions de stockage des œufs en Europe de l'ouest, n'influencent pas les taux de contamination (Messens et al 2006).

Bien que l'âge de la poule ait un impact sur les caractéristiques de la coquille, il n'a pas d'influence sur le taux de pénétration (Messens et al 2005, De Reu et al 2006b). Il en est de même pour la lignée de poules (ISA Brown Warren versus Bovan Goldline) et leur type de logement.

Les facteurs influençant la pénétration de la coquille semblent donc être essentiellement le niveau de contamination de l'œuf en surface (Chen et al 1996, Miyamoto et al 1998, Messens et al 2006 et 2007) et l'absence de fêlures ou de défaut de calcification de la coquille (Ernst et Fuqua 1998, Allen et Griffiths 2001).

\section{4 / Migration, survie et multi- plication des microorganismes dans le blanc}

Le blanc d'œuf, comparable à un liquide intra-cellulaire, constitue une importante ligne de défense contre les bactéries. Il sert de réserve nutritionnelle à l'embryon et, par le biais d'un arsenal de molécules et de mécanismes lui conférant des activités antimicrobiennes à très large spectre, il assure sa protection contre l'invasion par les microorganismes.

a) Rôle des molécules à activité antimicrobienne

\section{- Le lysozyme}

Le lysozyme, présent dans de nombreux fluides biologiques, est un composant important des systèmes de défense non spécifique des organismes. Il possède différents types d'activité bactéricide. Le premier et le mieux connu est son activité enzymatique d'hydrolyse du peptidoglycane des bactéries à coloration de Gram positive (dégradation de la liaison osidique $\beta(1-4)$ entre la $\mathrm{N}$-acétylglucosamine et l'acide $\mathrm{N}$-acétylmuramique) qui conduit à l'hydrolyse de la paroi suivie d'une lyse de la bactérie en cas de modification de l'osmolarité du milieu. Les bactéries à coloration de Gram négative sont résistantes à cette activité, en raison de la composition de leur peptidoglycane et de sa protection par la membrane externe. D'autres bactéries ont des peptidoglycanes modifiés qui leur confèrent aussi une résistance (Vollmer 2008). Un second mécanisme non lytique propre au lysozyme implique une activité de perturbation des membranes (Ibrahim et al 2001a) et un troisième, mis en évidence par Ibrahim et al (2001b), l'induction d'autolysines. Selon le type de bactéries (composition et structure des membranes et des parois, présence d'un facteur inhibiteur du lysozyme dans le cytoplasme, Monchois et al (2001) et des conditions environnementales, un de ces mécanismes peut prédominer et être à l'origine de la mort des cellules.

\section{- L'ovotransferrine}

L'ovotransferrine est une protéine chélatrice des ions métalliques qui appartient à la famille des transferrines présentes dans différents fluides animaux (transferrine du sang, lactoferrine du lait) et qui, en créant un environnement déficient en fer pour les bactéries, présente un effet bactériostatique. Ce mécanisme d'action correspond au mécanisme le mieux décrit (Garibaldi 1970, Baron et al 1997). Certains microorganismes, dont les entérobactéries et Salmonella, sont toutefois capables de synthétiser des chélateurs à haute affinité pour le fer, nommés sidérophores (Neilands 1981), leur permettant de pallier l'indisponibilité du fer. Un second mécanisme d'action de l'ovotransferrine, proposé par Aiguilera et al (2003), cible la fonction biologique de la membrane cytoplasmique. Les deux mécanismes sont dépendants de la concentration en fer du milieu, la saturation en fer éliminant l'effet bactériostatique.

\section{- Autres protéines du blanc d'œuf}

Les inhibiteurs de protéases comme la cystatine (inhibiteur des protéases à cystéine), l'ovomucoïde et l'ovoinhibiteur (inhibiteurs des protéases à sérine) et l'ovostatine (inhibiteur de nombreuses protéases) (Li Chan et Shuryo 1989, Stevens 1991), les protéines chélatrices de vitamines comme la flavoprotéine (fixant la riboflavine), l'avidine (fixant la biotine) et la «thiamin binding protein» (fixant la thiamine) sont aussi évoquées dans la littérature comme mises en jeu dans l'activité antimicrobienne du blanc d'œuf, même si leur rôle semble mineur. D'autre part, le blanc d'œuf contient probablement des protéines ou des peptides encore inconnus mis en jeu dans ces activités bactériostatiques ou bactéricides. L'apport de la génomique fonctionnelle, rendue possible par le séquençage du génome de la poule, devrait contribuer à la découverte de nouvelles molécules à activité antimicrobienne dans le blanc d'œuf (Gautron 2010). D'autres protéines non connues pour leurs propriétés antibactériennes peuvent développer ce type d'activités sous certaines conditions ou après hydrolyse. On peut donc imaginer que le blanc d'œuf puisse développer des activités antimicrobiennes différentes de celles habituellement connues sous certaines conditions (Baron et al 2007b). Il est important de considérer qu'il peut exister des interactions entre les molécules à activité antibactérienne (effet synergique) et entre ces molécules et les caractéristiques physico-chimiques du blanc d'œuf. Son $\mathrm{pH}$ alcalin et sa structure visqueuse et hétérogène en font en effet un environnement très particulier. Le $\mathrm{pH}$ est un facteur déterminant pour de nombreuses fonctions biologiques et particulièrement les activités enzymatiques et le statut des membranes. Il est possible que l'activité de certaines protéines soit modifiée au $\mathrm{pH}$ basique du blanc d'œuf. Par ailleurs, l'hétérogénéité du blanc d'œuf rend probablement difficile l'accès aux nutriments nécessaires à la croissance bactérienne. Ainsi, Li Chan et Shuryo (1989) montrent que le lysozyme peut immobiliser les bactéries et que les complexes ovotransferrine-fer ne sont sans doute pas répartis de manière homogène dans le blanc.

Le blanc d'œuf est donc un liquide biologique pauvre en éléments nutritifs accessibles aux microorganismes et possède sans aucun doute une grande variété de mécanismes de contrôle de la croissance des bactéries, plus ou moins spécifiques du type bactérien. Il semble ainsi évident que le rôle de l'ovotransferrine et de la carence en fer soit prédominant pour Salmonella Enteritidis (Garibaldi 1970, Baron et al 1997, Kang et al 2006). D'autres bactéries semblent insensibles à ces mêmes facteurs. Ainsi, Wang et Shelef (1991) mettent en avant le rôle du lysozyme et du $\mathrm{pH}$ alcalin dans l'inhibition de Listeria dans le blanc d'œuf.

Le blanc d'œuf a un effet fortement sélectif sur les microorganismes. La plus forte fréquence de contamination du contenu des œufs par Salmonella Enteritidis pourrait s'expliquer par le fait que cette bactérie possède des avantages pour survivre dans le blanc ou pour coloniser l'appareil reproducteur des poules (Clavijo et al 2006). En réponse à l'activité antimicrobienne du blanc d'œuf, les microorganismes, et notamment les pathogènes, développent des parades plus ou moins efficaces. On peut citer l'exemple de la production, par certains pathogènes, de molécules capables de capter le fer chélaté par l'ovotransferrine. Pour d'autres, les adaptations de la composition du peptidoglycane rendent l'action du lysozyme inefficace (Baron et al $2007 \mathrm{~b}$ pour revue).

b) Influence des conditions environnementales

La croissance dans le blanc et la migration vers le jaune dépendent du microorganisme mais aussi de l'état des 
œufs et, plus globalement, des conditions de stockage (temps et température).

Duboccage et al (2001) montrent que la croissance de Salmonella est favorisée à $20^{\circ} \mathrm{C}$ pour des œufs de moins d'une semaine, par comparaison avec des œufs stockés à cette température pendant 2 à 3 semaines. Après trois semaines, la croissance serait à nouveau favorisée dans l'œuf, sans doute en raison de l'altération de la membrane vitelline et de la diminution de la viscosité, dues à la déstructuration du complexe ovomucine-lysozyme à $\mathrm{pH}$ alcalin (passage d'un $\mathrm{pH}$ 7,6 à environ 9,3 suite à la perte de dioxyde carbone quelques jours après la ponte). Ces deux facteurs favorisent le passage des nutriments du jaune vers le blanc et la migration de Salmonella vers le jaune (Humphrey et Whitehead 1993, Chen et al 2005).

La température de stockage joue elle aussi un rôle important. A des températures inférieures à $8^{\circ} \mathrm{C}$, la croissance de Salmonella ne semble pas possible (Ruzickova 1994, Schoeni et al 1995) et on observe même un effet bactéricide avec disparition de la population à $4^{\circ} \mathrm{C}$ en quelques jours (Lock et Board 1992, Schoeni et al 1995, Chen et al 2005). La même observation est faite à $10^{\circ} \mathrm{C}$ par Clay et Board (1991) et Chen et al (2005), alors que Schoeni et al (1995) observent une légère croissance. Entre $20^{\circ} \mathrm{C}$ et $30^{\circ} \mathrm{C}$, les auteurs observent une croissance d'une à quatre unités logarithmiques en fonction des températures et des temps d'incubation (Lock et Board 1992, Baron et al 1997, Chen et al 2005, Murase et al 2005). Pour des températures supérieures à $37^{\circ} \mathrm{C}$, les auteurs observent un effet bactéricide plus ou moins important selon la température et le temps d'incubation (Tranter et Board 1984, Bradshaw et al 1990, Clavijo et al 2006, Kang et al 2006). Ces travaux suggèrent que certaines activités enzymatiques sont amplifiées à des températures supérieures à $37^{\circ} \mathrm{C}$ et provoque la mort des bactéries.

\section{5 / Migration et multiplication des microorganismes dans le jaune}

$\mathrm{Au}$ cours du temps, les chalazes et le blanc se liquéfient et n'assurent plus le maintien du jaune en position centrale, ce qui réduit la distance entre le jaune et la coquille et favorise l'accès des microorganismes au jaune. La membrane vitelline qui contient, entre autres protéines spécifiques, du lysozyme et de l'ovomucine, constitue cependant un dernier obstacle à la migration (Chen et al 2005). Elle laisse passer des solutés du jaune vers le blanc et, notamment, du fer et des acides aminés. Différents auteurs ont montré que ces échan- ges permettaient la prolifération de Salmonella inoculée dans le blanc à proximité du jaune (Gast et Holt 2000b, Grijspeerdt et al 2005, Murase et al 2005). Ces échanges sont d'autant plus importants que l'œuf vieillit, en raison de l'altération de la membrane vitelline évoquée dans le paragraphe précédent, mais peuvent être maîtrisés par un stockage des œufs aux températures de réfrigération (Gast et Holt 2001, Gast et al 2006). De façon similaire, il semble que la pénétration n'ait jamais été observée à $42^{\circ} \mathrm{C}$, température de formation de l'œuf (Guan et al 2006).

Si les bactéries atteignent le jaune, leur croissance y est très rapide pour des températures supérieures ou égales à $25^{\circ} \mathrm{C}$ (Ruzickova 1994, Schoeni et al 1995, Gast et Holt 2000b et 2001, Gumudavelli et al 2007), plus réduite à $10^{\circ} \mathrm{C}$ (Gast et Holt 2000b, Gumudavelli et al 2007) et ne serait plus possible pour Salmonella à $7^{\circ} \mathrm{C}$ (Gumudavelli et al 2007). Le stockage des œufs à des températures de réfrigération représente donc une solution efficace pour ralentir la perte de l'intégrité de la membrane vitelline, réduire l'accessibilité du jaune aux bactéries et limiter leur multiplication dans le jaune.

\section{6 / Moyens de maîtrise de la contamination des oufs}

Différents moyens ont été explorés pour réduire les taux de contamination des œufs, de l'amont (sélection des poules et pratiques d'élevage) à l'aval (conditionnement, transport et stockage des œufs).

\section{a) Sélection génétique}

Berthelot et al (1998) ont montré qu'il existe une base génétique héritable impliquée dans la résistance au portage caecal de $S$. Enteritidis chez la poule. De même, Sadeyen et al (2006) notent, en comparant 2 lignées de poules différant dans leur sensibilité au portage de salmonelles, une expression significativement plus forte de certains gènes codant des protéines mises en jeu dans la défense de la poule contre la colonisation par Salmonella. Ainsi, par la sélection, il semblerait possible d'améliorer la résistance des poules au portage de Salmonella. Une étude récente décrit les paramètres à prendre en compte (Beaumont et al 2008).

En ce qui concerne les œufs, certains auteurs pensent que l'activité bactéricide du blanc d'œuf (Vidal et al 2003 , Sellier et al 2007), mais surtout la solidité de la coquille (Dunn et al 2005) ont également une composante génétique. Ces paramètres pourraient donc faire l'objet d'une amélioration par un programme de sélection.

\section{b) Pratiques d'élevage}

De façon générale, le stress généré chez les poules dans les élevages est connu pour jouer un rôle dans la susceptibilité à contracter une salmonellose et dans l'induction de défauts de calcification de la coquille. Au pic de ponte, le stress semble en effet responsable d'une diminution des défenses immunitaires et de l'afflux des macrophages vers les organes reproducteurs, favorisant la contamination des ovaires (Wigley et al 2005, Li et al 2007).

\section{- Modes d'élevage}

Il semble qu'une taille élevée de troupeau soit le facteur de risque prépondérant de contamination des poules par $S$. Enteritidis. Le type de logement ou l'aménagement des cages peuvent aussi avoir une influence sur ce portage et sur le nombre d'œufs fêlés ou cassés (Mallet et al 2005, De Reu et al 2005, Mallet 2010). L'avènement des cages aménagées, dont la mise en place doit s'achever en 2012, et la suppression programmée des logements en cages conventionnelles, ne doivent pas faire l'économie du maintien, voire de l'augmentation de la qualité des œufs. Des améliorations peuvent être apportées sur l'agencement des aménagements et sur le design d'éléments comme le perchoir.

- Nettoyage et désinfection des bâtiments

Sachant que la teneur en flore mésophile à la surface des coquilles est liée au niveau de contamination de l'air dans l'enceinte de l'élevage (De Reu et al 2005), il paraît déterminant de limiter l'empoussièrement et de favoriser une bonne hygiène dans les bâtiments d'élevage. La décontamination des bâtiments d'élevage entre deux bandes de poules pondeuses est aujourd'hui quasi systématique, mais elle n'est obligatoire qu'en cas de contamination avérée par $S$. Enteritidis ou Typhimurium (HuneauSalaün et al 2005). Etant donné la contribution de nombreuses espèces d'animaux sauvages (poux, mouches, souris) en tant que réservoirs et vecteurs de Salmonella Enteritidis dans les élevages, les mesures prises pour limiter leur entrée ou les éradiquer sont aussi importantes.

\section{- Vaccination des poules contre}

\section{$S$. Enteritidis}

La vaccination est encouragée par les autorités sanitaires européennes. Elle est obligatoire depuis le $1{ }^{\mathrm{er}}$ janvier 2008 dans les pays de la Communauté Européenne montrant une prévalence en Salmonella supérieure à $10 \%$. La vaccination est probablement une mesure importante de prévention pour réduire le niveau de contamination des poules mais il manque des données 
scientifiques permettant de vérifier son efficacité sur la réduction du taux de contamination des œufs.

\section{- Alimentation des poules}

On trouve sur le marché une large gamme d'additifs alimentaires antiSalmonella destinés aux poules pondeuses. Ces additifs ont pour vocation de réduire la colonisation du tractus digestif des poules et, par voie de conséquence, l'excrétion fécale. Ainsi, en diminuant les taux de contamination de l'environnement, ces additifs peuvent diminuer le risque de contamination horizontale. Des préparations à base d'acides organiques à chaîne courte (notamment les acides propionique, butyrique et formique) ou à chaîne moyenne (acides caproïque, caprylique, caprique et laurique) sont commercialisées (Van Immerseel et al 2004, Gantois et al 2006, Thomar et al 2006).

Une autre stratégie consiste à entraver le développement de Salmonella dans le système digestif de la poule par l'addition de pré- ou de probiotiques dans l'alimentation. Les prébiotiques sont des composants alimentaires naturels non digestibles censés améliorer la santé en influençant favorablement la flore intestinale par une stimulation sélective de certaines bactéries déjà présentes dans l'intestin (Gibson et Roberfroid 1995). On peut citer l'utilisation de fructo-oligosaccharides pour le développement des bifidobactéries qui permettent de diminuer la colonisation par Salmonella. D'autres molécules font l'objet d'études ou d'essais. Les probiotiques sont quant à eux des microorganismes vivants qui, lorsqu'ils sont administrés en quantité adéquate, produisent un bénéfice pour la santé de l'hôte. Certaines études, en particulier avec des flores lactiques, ont déjà été réalisées (Van der Wielen et al 2002, Tayeb et al 2007).

L'efficacité de l'utilisation de ces additifs sur les taux de contamination des œufs n'est pas connue et il faut rester prudent dans la mise en œuvre de ces pratiques, en particulier quand des microorganismes vivants sont mis en jeu.

En conclusion, pour garantir un faible taux de contamination des œufs, les bonnes pratiques d'élevage et les mesures spécifiques du programme national de lutte et de surveillance contre les infections à Salmonella doivent être appliquées de manière rigoureuse.

\section{c) Collecte, tri et conditionnement des oufs}

Pour la collecte des œufs en élevage, le tri et l'emballage dans les centres de conditionnement et le stockage avant expédition, les exploitants doivent aussi respecter de bonnes pratiques. Au niveau des locaux, les contaminations croisées doivent être évitées en assurant une marche en avant des œufs et en prévenant la contamination par le personnel, les surfaces et les nuisibles. La maîtrise des risques de choc et de souillure des œufs permet, à chaque étape, d'éviter la détérioration de la coquille. Des mesures spécifiques aux centres de tri peuvent être mises en place, telles que le mirage et le tri des oufs fêlés et cassés. L'analyse des microfêlures et de la fragilité de la coquille reste toutefois un point faible. De nombreuses technologies d'analyse de la coquille ont déjà été testées (De Ketelaere et al 2004) et d'autres techniques actuellement en cours d'étude pourront être utiles pour réduire, à la source, les œufs fragilisés.

Il est nécessaire de limiter les chocs thermiques à toutes les étapes, de la collecte des œufs chez le producteur à la livraison au centre de tri. En France, les œufs doivent être stockés entre $5^{\circ} \mathrm{C}$ et $25^{\circ} \mathrm{C}$. L'utilisation de salles de stockage climatisées et un transport en camion isotherme permettraient de minimiser les écarts de température. Il pourrait être intéressant de refroidir l'œuf dans les premières heures suivant la ponte et de maintenir une chaîne du froid jusqu'au consommateur pour limiter la pénétration, la migration et la multiplication de Salmonella dans l'œuf. Nous avons déjà évoqué l'intérêt de la réfrigération dans la maîtrise du développement de Salmonella. Ce moyen de stabilisation est facile à mettre en œuvre mais il implique une modification profonde de la logistique, de l'éleveur au consommateur, et un changement de rayonnage dans les grandes et moyennes surfaces (rayon réfrigéré).

\section{d) Décontamination des oufs}

Le lavage des œufs de table (œufs de catégorie A) est courant dans de nombreux pays mais n'est pas pratiqué en Europe en dehors de la Suède. Les arguments en faveur de cette pratique sont la diminution du degré de contamination de la coquille et donc du degré de contamination interne (Lucore et al 1997, Hutchison et al 2004, Jones et al 2004). Les détracteurs de ces pratiques invoquent la fragilisation des barrières externes de l'œuf, telles que la cuticule, et une perte en eau (Kim et Slavik 1996, Wang et Slavik 1998, Favier et al 2001), favorisant la pénétration et augmentant le degré de contamination interne (Haines et Morand 1940, Lorenz et Starr 1952).

Dans un rapport de l'Efsa (Efsa 2007), cette pratique est critiquée en tant qu'outil pouvant résoudre un problème d'hygiène publique. Cependant, vu l'évolution de la maîtrise des technologies de lavage, l'augmentation du nombre d'études récentes favorables au lavage et l'efficacité du lavage dans les pays qui le pratiquent sur des œufs triés (Suède), l'autorisation du lavage pourrait finalement aboutir en Europe.

La «pasteurisation» des œufs coquille, c'est-à-dire des œufs intègres possédant encore leur coquille, a fait l'objet de diverses études et des technologies brevetées sont appliquées aux Etats-Unis. Braden (2006) pensent qu'un traitement thermique permettrait de réduire les cas de salmonelloses liées à l'œuf coquille aux Etats-Unis mais cette estimation a été faite dans le contexte américain et donc sur des œufs lavés puis refroidis après traitement thermique. L'extrapolation à l'Europe est donc difficile.

D'autres traitements de décontamination ont été étudiés ou sont en cours d'étude : traitements «flashs» à base d'eau chaude ou de vapeur, traitements aux UV, à l'ozone, aux radiations, aux ultrasons, à l'eau électrolysée ou encore à l'air ionisé (plasma).

Pour l'ensemble de ces techniques de décontamination, il convient de souligner qu'il est nécessaire de les valider dans les conditions naturelles de contamination et à l'échelle industrielle, en gardant en mémoire la nécessité d'étudier leur bénéfice en termes de santé publique.

Pour conclure sur la microbiologie de l'œuf, on peut dire qu'il possède un arsenal de molécules et de mécanismes destinés à limiter ou à réduire la croissance et la pénétration des bactéries d'origine endogène ou exogène. Les pratiques d'élevage, de stockage et de conditionnement doivent éviter l'apport de nouvelles contaminations, la multiplication des bactéries présentes et l'endommagement des défenses antimicrobiennes naturelles de l'œuf. Une bonne connaissance des propriétés antimicrobiennes et des microorganismes contaminants, ainsi que le respect des bonnes pratiques d'hygiène, de l'élevage à la commercialisation, doivent garantir une qualité microbiologique satisfaisante.

\section{2 / Microbiologie des ovo- produits}

Une part croissante de la production d'œufs est transformée par l'industrie des ovoproduits. Les ovoproduits désignent l'ensemble des produits obtenus à partir de l'œuf, de ses composants ou de 
leur mélange, après élimination de la coquille et des membranes coquillières, et destinés à la consommation humaine. On peut trouver de l'entier nature, liquide, concentré ou séché, cristallisé, congelé, surgelé ou coagulé. En raison de leurs propriétés fonctionnelles (pouvoir moussant, liant, gélifiant, colorant), ces produits entrent dans la confection de nombreux aliments (pâtisseries, charcuteries, confiseries...). Bien que le contenu de l'œuf provenant d'un élevage sain soit en général stérile, le cassage entraîne systématiquement la contamination du blanc et du jaune par contact avec les coquilles souillées, conduisant ainsi à des ovoproduits très périssables. De nombreux microorganismes peuvent ainsi contaminer les ovoproduits. La maîtrise de leur qualité microbiologique est un impératif, en particulier lorsqu'ils sont intégrés dans des aliments crus ou peu cuits. Dans ce sens, la qualité des œufs utilisés, les pratiques d'hygiène et les opérations technologiques mises en œuvre sont déterminantes.

\section{1 / Réception des œufs coquille}

Les œufs destinés au cassage peuvent provenir d'élevages contrôlés par les services vétérinaires, des centres de conditionnement ou de l'importation. Les contrôles à la réception portent sur l'aspect extérieur des emballages, l'aspect des œufs et éventuellement sur leur fraîcheur, ce dernier paramètre permettant de garantir l'intégrité de la membrane vitelline. L'état de fraîcheur est estimé par mesure de la hauteur de l'albumen épais, exprimée en unités Haugh, sachant que le nombre d'unités diminue avec le temps de stockage (Sauveur 1988). L'état de fraîcheur et le pourcentage d'œufs sales ou fêlés sont des paramètres essentiels à la maîtrise de la contamination finale.

\section{2 / Stockage des oufs coquille}

Les œufs sont stockés dans des locaux climatisés (en général à $15^{\circ} \mathrm{C}$ ) ou en chambre froide à $4^{\circ} \mathrm{C}$, selon la durée du stockage. Des bonnes conditions de stockage (notamment températures basses et constantes, hygrométrie contrôlée, locaux hygiéniques) sont essentielles pour limiter l'apport de microorganismes, la pénétration, la migration et la multiplication des microorganismes dans l'œuf.

Le lavage des œufs destinés à la fabrication d'ovoproduits est autorisé par l'Union Européenne, contrairement aux œufs de table, mais il n'est pas réalisé en France en raison du surcoût engendré et d'un manque de données montrant son efficacité en termes de santé publique.

\section{3 / Cassage des œufs}

Les machines de cassage assurent le cassage des œufs, l'élimination des coquilles et éventuellement la séparation du blanc du jaune. Le contact avec les coquilles et les surfaces des machines entraîne une contamination systématique du contenu de l'œuf qui, une fois cassé, perd une grande partie de ses défenses antimicrobiennes naturelles. L'entier et le jaune sont en effet des milieux parfaitement adaptés au développement des microorganismes. Le blanc limite la croissance de par ses propriétés antibactériennes, à condition qu'elles ne soient pas compromises par la présence, ne serait-ce que de traces de jaune, accompagnées de fer et de nutriments (Baron et al 1997).

Les coquilles sont rapidement évacuées pour minimiser le contact avec l'ovoproduit. Elles sont ensuite broyées et centrifugées. Ces opérations doivent être séparées physiquement du procédé de fabrication pour éviter les contaminations croisées. Après cassage, les ovoproduits sont soumis à un tamisage grossier et à une filtration permettant de parfaire l'homogénéisation et d'éliminer les débris de coquilles et les chalazes.

Les procédures de nettoyage et de désinfection des machines doivent être efficaces pour éviter l'apport de microorganismes et la formation de biofilms, notamment au niveau du filtre où l'accumulation des débris de coquille est souvent source de contamination.

\section{4 / Transformation et/ou stabi- lisation des ovoproduits}

Après cassage, les ovoproduits subissent différentes opérations de séparation, de transformation et/ou de stabilisation, en fonction de leur destination : pasteurisation, sucrage, salage, congélation, concentration, séchage. Ces opérations ont un effet stabilisant, soit par destruction, soit par inhibition du développement des microorganismes présents.

\section{a) Destruction des microorganismes}

Dans l'industrie des ovoproduits, la destruction des microorganismes est essentiellement réalisée par traitement thermique. Les traitements généralement appliqués en France sont de l'ordre de 65 à $68^{\circ} \mathrm{C}$ pendant 5 à 6 min pour l'entier et le jaune. Pour le blanc liquide, le traitement est beaucoup plus faible, de l'ordre de 55 à $57^{\circ} \mathrm{C}$ pendant 2 à $5 \mathrm{~min}$, en raison de la très grande thermosensibilité des protéines. Ces barèmes permettent des niveaux de destruction satisfaisants pour les flores végétatives, mais sont inefficaces sur les flores thermorésistantes et notamment les formes sporulées.
Concernant les microorganismes pathogènes, de nombreuses études de thermorésistance ont été réalisées sur $S$. Enteritidis, étant donné son importance dans la filière et, plus récemment, sur Listeria, connue pour être plus résistante que $S$. Enteritidis. Les études sont très difficilement comparables car la thermorésistance dépend, entre autre, de la souche, des conditions de culture et d'inoculation et du matériel utilisé pour le traitement thermique. Pour Salmonella, les valeurs de $\mathrm{D}$ (temps de réduction décimale à une température donnée, c'està-dire temps nécessaire pour réduire la population au dixième de sa valeur initiale) recensées dans la littérature pour l'entier vont de 0,22 à 0,44 min à $60^{\circ} \mathrm{C}$, pour le jaune de 0,27 à 0,35 min à $63^{\circ} \mathrm{C}$ et pour le blanc de 1,7 à 2,1 min à $57^{\circ} \mathrm{C}$ (Humphrey et al 1990 , Shah et al 1991, Denis et al. 1995, Palumbo et al 1995 et 1996, Doyle et Mazzotta 2000). Pour Listeria, les valeurs de $\mathrm{D}$ de la littérature varient pour l'entier de 1,3 à $2,1 \mathrm{~min}$ à $60^{\circ} \mathrm{C}$, pour le jaune de 0,7 à $2,3 \min$ à $63^{\circ} \mathrm{C}$ et pour le blanc de 4,35 à 20,9 min à $57^{\circ} \mathrm{C}$ (Foegeding et Stanley 1990, Bartlett et Hawke 1995, Muriana et al 1996, Knight et al 1999, Michalski et al 2000, Doyle et al 2001). A partir de ces données et des valeurs de $z$ (augmentation de température nécessaire pour diviser le temps de réduction décimale par dix) fournies par ces mêmes auteurs, on peut confirmer que les barèmes couramment utilisés en France pour l'entier et le jaune sont suffisamment efficaces contre Salmonella et Listeria. Ils ont cependant une efficacité insuffisante dans le blanc vis-à-vis de ces deux bactéries. On peut rappeler toutefois que le blanc n'est pas un milieu propice au développement des microorganismes.

Dans le cas du virus de l'Influenza aviaire, les protocoles de pasteurisation classiquement appliqués par l'industrie pour les produits liquides à base d'œufs, permettent une inactivation efficace du virus, d'après l'Organisation Mondiale de la Santé (OMS).

D'autres traitements ont fait l'objet d'études ou d'applications industrielles, en particulier pour le blanc d'œuf pour lequel le traitement thermique est insuffisant. En France, la réglementation autorise l'irradiation des ovoproduits liquides, séchés et congelés avec des doses de $3 \mathrm{kGy}$ mais ce traitement n'a pas ou que peu d'applications dans la filière des ovoproduits, en raison d'une mauvaise image auprès du consommateur. Des procédés tels que les champs électriques pulsés ont été développés récemment mais ont fait l'objet d'un nombre limité d'études. 


\section{b) Inhibition des microorganismes}

L'activité de l'eau $\left(\mathrm{a}_{\mathrm{w}}\right)$ représente une mesure indirecte de la quantité d'eau libre présente dans une matrice. Les bactéries ne peuvent se développer en dessous d'une $\mathrm{a}_{\mathrm{w}}$ de 0,91 alors que les levures et les moisissures peuvent se développer jusqu'à des $a_{w}$ de 0,65 . Aucun microorganisme ne peut se développer en dessous d'une $\mathrm{a}_{\mathrm{w}}$ de $0,6 \mathrm{La}$ diminution de l'activité de l'eau est donc un moyen de stabiliser les ovoproduits.

Dans ce cadre, la concentration et le séchage permettent d'éliminer l'eau du produit et, en premier lieu, l'eau faiblement liée donc disponible. Dans le cas de la concentration des ovoproduits, les niveaux de concentration atteints ne réduisent toutefois que faiblement l'activité de l'eau et n'ont donc que peu d'influence sur le développement des microorganismes. Le séchage des ovoproduits permet au contraire d'obtenir une poudre avec une $\mathrm{a}_{\mathrm{w}}$ comprise entre 0,2 et 0,3 , qui n'autorise donc aucun développement microbien.

L'addition de sucre ou de sel (très hydrophiles) limite elle aussi la disponibilité de l'eau pour les microorganismes. Les niveaux d'addition peuvent atteindre $50 \%$ pour le sucre et $10 \%$ pour le sel, ce qui permet d'abaisser l'activité de l'eau à des valeurs inférieures à 0,85 .

En ce qui concerne l'ajout d'inhibiteurs bactériens, seuls l'acide sorbique et l'acide benzoïques sont autorisés pour les ovoproduits liquides, à raison de 5 g. $\mathrm{kg}^{-1}$. Ils ont une activité bactéricide et antifongique.

Alors que la congélation rend l'eau indisponible pour les bactéries en raison de sa solidification (glace), la cinétique de croissance des microorganismes et la production de toxines par les bactéries pathogènes est ralentie par la réfrigération, couramment utilisée dans le secteur agro-alimentaire. L'extension des pratiques de réfrigération a amélioré la qualité et la durée de vie des produits mais est aussi responsable de la sélection d'une flore psychrotrophe. Parmi les microorganismes psychrotrophes à l'origine de toxi-infections alimentaires, on trouve Listeria monocytogenes, Yersinia enterolitica, Bacillus cereus et Clostridium botulinum de type E. Parmi les bactéries psychrotrophes responsables d'altérations, on trouve de manière prépondérante les Pseudomonas mais aussi les genres Shewanella, Alcaligenes, Acinetobacter, Aeromonas, Flavobacterium, Enterobacter, Serratia, Hafnia, Micrococcus et Brochothrix (Bornert 2000). Une température de $2^{\circ} \mathrm{C}$ assure une maîtrise très efficace du développement de ces bactéries mais de très faibles variations de température peuvent présenter des risques, sachant qu'une activité métabolique peut être observée dès $4^{\circ} \mathrm{C}$, même à de très faibles taux de croissance. La production de lipases et de protéases par certaines bactéries psychrotrophes peut être responsable de l'altération du produit, d'autant plus que ces enzymes peuvent être plus thermorésistantes que le microorganisme qui les produit. La production de toxines est quant à elle stoppée chez la plupart des microorganismes aux températures de réfrigération, en dehors de certaines bactéries psychrotrophes. Baron et al (2007a) ont observé une production d'entérotoxines par une souche de Bacillus weihenstephanensis (du groupe Bacillus cereus) après 21 jours d'incubation à $6^{\circ} \mathrm{C}$ et 7 jours d'incubation à $8^{\circ} \mathrm{C}$ dans de $l^{\prime} œ u f$ entier liquide correspondant à une population élevée $\left(10^{5,1} \mathrm{ufc} / \mathrm{mL}\right)$.

Il apparaît donc que la maîtrise des températures de réfrigération (inférieures à $4^{\circ} \mathrm{C}$ ) tout au long de la chaîne de fabrication et jusqu'à la distribution est indispensable à la maîtrise de ces flores.

\section{5 / Contamination des ovo- produits}

La flore des ovoproduits dépend essentiellement de celle des œufs d'origine et est fortement influencée par les procédés de transformation et de stabilisation, comme on l'a vu dans le paragraphe précédent.

Une étude exhaustive de la contamination de l'œuf entier liquide cru et pasteurisé en cours de conservation a été réalisée de 2001 à 2003 dans l'Ouest de la France (Protais et al 2006). Après pasteurisation, le nombre de microorganismes diminue et les échantillons respectent les critères microbiologiques réglementaires. La pasteurisation permet de réduire considérablement le nombre d'entérobactéries, d'E. Coli et de bactéries des genres Brochothrix, Pseudomonas et Campylobacter et la présence de Salmonella et Listeria. Pour Salmonella, $0,47 \%$ des échantillons d'ovoproduits analysés sont positifs à l'échelle nationale (Efsa 2007). D'autre part, Moore et Madden (1993) n'ont pas retrouvé de Listeria après enrichissement de 500 échantillons prélevés après pasteurisation, alors que la bactérie était présente dans les échantillons crus. Les streptocoques, les entérocoques et les spores de Bacillus semblent moins affectés par la pasteurisation. Les spores de Bacillus sont présentes à un faible niveau, à la fois pour le cru et pour l'entier pasteurisé $\left(10^{0,63}\right.$ et $10^{0,48} \mathrm{ufc} / \mathrm{mL}$, respectivement) mais le taux d'échan- tillons contaminés est de $58 \%$ pour l'entier cru et de $54 \%$ après pasteurisation. Les barèmes de pasteurisation sont donc, comme attendu, inefficaces sur ces bactéries sporulées. La présence de Bacillus dans les ovoproduits préoccupe particulièrement les industriels en raison de sa capacité à produire des enzymes à l'origine d'altérations aux conséquences économiques non négligeables. De plus, certaines espèces de Bacillus (du groupe Bacillus cereus, notamment) peuvent produire des toxines et être responsables de toxi-infections alimentaires. Ces bactéries ubiquistes sont difficiles à éliminer en raison de leur thermorésistance (la pasteurisation est inefficace et peut déclencher la germination des spores) et de leurs fortes capacités d'adhésion qui leur permettent de s'installer en biofilms dans les installations. Enfin, certaines souches psychrotrophes sont capables de se multiplier à des températures de l'ordre de 4 à $6^{\circ} \mathrm{C}$. Récemment, Baron et al (2007a) ont isolé une bactérie psychrotrophe appartenant au groupe Bacillus cereus, à partir d'un échantillon altéré d'entier liquide. Cette étude a montré que la bactérie était capable de se développer dans de l'entier liquide et d'y produire des toxines, même à des températures de réfrigération, et qu'elle présentait des capacités d'adhésion lui permettant de former des biofilms (cf. photo).

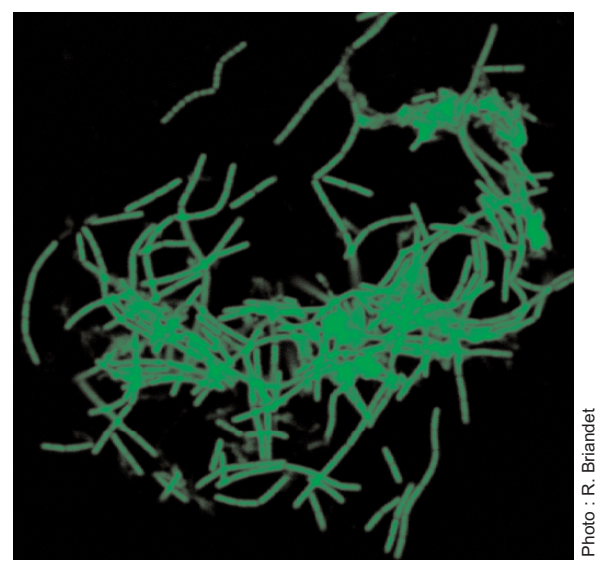

\section{6 / Survie et multiplication des microorganismes dans les ovoproduits}

Pour Salmonella, entre $4^{\circ} \mathrm{C}$ et $10^{\circ} \mathrm{C}$, la croissance dans le jaune (Gumudavelli et al 2007), l'entier (Abdel Karem et Mattar 2001) ou le blanc (Clay et Board 1991, Lock et Board 1992, Ruzickova 1994, Schoeni et al 1995, Chen et al 2005) ne semble pas possible ou seulement à très faible taux. Entre $20^{\circ} \mathrm{C}$ et $30^{\circ} \mathrm{C}$, les croissances les plus faibles sont observées dans le blanc, allant de 1 à 4 unités logarithmiques en fonction des températures et des temps d'incubation, les croissances les plus fortes sont observées dans le jaune, 
allant de 7 à 8 unités logarithmiques en moins de 2 jours d'incubation (cf. $\S 1.4$ $b$ et 1.5$)$.

La croissance de Listeria, bien que lente, est possible aux températures de réfrigération dans les trois types d'ovoproduits. Pour le jaune et l'entier placés à $4^{\circ} \mathrm{C}$, la population augmente de 2 à 12 unités logarithmiques en 3 semaines, suivant les auteurs (Foegeding et Leasor 1990, Notermans et al 1991). Dans le blanc, Notermans et al (1991) ont constaté un effet bactériostatique à cette température. Pour des températures supérieures à $20^{\circ} \mathrm{C}$, la croissance est rapide dans le jaune avec une augmentation de 3 unités logarithmiques en 1 jour à $22^{\circ} \mathrm{C}$ contre 2 unités logarithmiques après 2 à 9 jours dans l'entier et aucune croissance dans le blanc.

Baron et al (2007a) ont étudié le comportement, dans de l'entier liquide, d'une souche psychrotrophe appartenant au groupe Bacillus cereus isolée d'un lot d'entier altéré. La population bactérienne augmente de 2 unités logarithmiques après 7 jours à $8^{\circ} \mathrm{C}$ et 14 jours à $6^{\circ} \mathrm{C}$, contre 4,5 unités logarithmiques à $10^{\circ} \mathrm{C}$ en moins de 7 jours. En revanche, aucun développement n'est observé à $4{ }^{\circ} \mathrm{C}$.

\section{7 / Moyens de maîtrise de la contamination}

Le comportement des microorganismes dans un ovoproduit dépend de la nature de l'ovoproduit (liquide, séché, concentré, additionné de sel ou de sucre), de son niveau de contamination initial et surtout de la température. Globalement, on peut donc dire que le jaune et l'entier permettent une croissance rapide dès que les températures de réfrigération ne sont pas respectées alors que le blanc a, en général, un effet bactéricide ou bactériostatique.

Une bonne maîtrise de la majorité des espèces pathogènes et notamment de Salmonella dans le secteur des ovoproduits est assurée par le respect des règles d'hygiène et la pasteurisation. On peut noter que pour le blanc, les barèmes de pasteurisation appliqués ne sont, dans l'absolu, pas suffisants mais la contamination du blanc d'œuf et le développement des microorganismes y sont naturellement très limités.

Les industriels doivent désormais s'attacher à maîtriser les espèces psychrotrophes, thermorésistantes et/ou sporulées potentiellement sélectionnées par les procédés de transformation et de stabilisation. L'un des meilleurs leviers est probablement la rigoureuse maîtrise de la chaîne du froid, de la production jusqu'à la consommation des produits.

\section{Conclusion}

Les propriétés antimicrobiennes de l'œuf en font un remarquable modèle physiologique de défense contre la pénétration et la prolifération des microorganismes. Afin de maintenir les faibles taux de contamination naturels de l'œuf, les pratiques de sélection et d'élevage des poules ainsi que celles du conditionnement des œufs doivent être parfaitement maîtrisées. Tout nouveau programme de sélection, toute nouvelle pratique ou opération technologique doivent être réfléchis en ce sens. Le cassage entraîne une contamination quasi inévitable du contenu de l'œuf et une perte d'une grande partie de ses défenses naturelles. Il est donc essentiel, pour maîtriser la qualité microbiologique des ovoproduits, de respecter les bonnes pratiques d'hygiène et de maîtriser les procédés de stabilisation. Enfin, il convient de souligner l'importance de la maîtrise des températures pour le contrôle des microorganismes pathogènes et les flores d'altération psychrotrophes, à la fois dans les ovoproduits et dans les œufs.

\section{Références}

Abdel Karem H., Mattar Z., 2001. Heat resistance and growth of Salmonella Enteritidis, Listeria monocytogenes and Aeromonas hydrophila in whole liquid egg. Acta Microbiol. Pol., 50, 27-35.

Aguilera O., Quiros L.M., Fierro J.F., 2003. Transferrins selectively cause ion efflux through bacterial and artificial membranes. FEBS Lett., 548, 5-10.

Ahlborn G., Sheldon B.W., 2005. Enzymatic and microbiological inhibitory activity in eggshell membranes as influenced by layer strains and age and storage variables. Poult. Sci., 84, 1935-1941.

Allen K.J., Griffiths M.W., 2001. Use of luminescent Campylobacter jejuni ATCC 33291 to assess eggshell colonization and penetration in fresh and retail eggs. J. Food Prot., 64, 2058-2062

Baron F., Gautier M., Brulé G., 1997. Factors involved in the inhibition of growth of Salmonella Enteritidis in liquid egg white. J. Food Prot., 60, 1394-1471.

Baron F., Cochet M.F., Grosset N., Madec M.N., Briandet R., Dessaigne S., Chevalier S., Gautier M., Jan S., 2007a. Isolation and characterization of a psychrotolerant toxin producer Bacillus weihenstephanensis, in liquid egg products. J. Food Prot., 70, 2782-2791.

Baron F., Réhault S., Nau F., 2007b. Compounds with antibacterial activity. In Bioactive egg compounds: characterization and application; Huopalathi R., Lopez-Fandino R., Anton M., Schade R. (Eds). Springer, Heidelberg, 191-196.

Bartlett F.M Hawke A.E., 1995. Heat resistance of Listeria monocytogenes Scott A and HAL $957^{\mathrm{E}_{1}}$ in various liquid egg products. J Food Prot., 58, 1211-1214.

Beaumont C., Lecerf F., Protais J., Calenge F. Prevost K, Lalmanach A.C., Chapuis H., Pitel F., Burlot T., Sellier N., Fravallo P., Vignal A., Velge P., 2008. An integrated approach of genetic resistance to Salmonella carrier state in fowls: from genetics to genomics and modelling. Dev. Biol., 132, 353-357.

Berthelot F., Beaumont C., Mompart F. Girard-Santosuosso O., Pardon P., DuchetSuchaux M., 1998. Estimated heritability of the resistance to cecal carrier state of Salmonella enteritidis in chickens. Poult. Sci., 77, 797-801.

Bornert G., 2000. Importance des bactéries psychrotrophes en hygiène des denrées alimentaires. Rev. Méd. Vét., 151, 1003-1010.

Braden C.R., 2006. Salmonella enterica serotype Enteritidis and eggs: a national epidemic in the United States. Clin. Infect. Dis., 43, 512-517.

Bradshaw J., Shah D.B., Forney E., Madden J.M., 1990. Growth of Salmonella Enteritidis in yolk of shell eggs from normal and seropositive hens. J. Food Prot., 53, 1033-1036.

Chen J., Clarke R.C., Griffiths M.W., 1996. Use of luminescent strains of Salmonella
Enteritidis to monitor contamination and survival in eggs. J. Food Prot., 59, 915-921.

Chen J., Shallo Thesmar H., Kerr W.L., 2005. Outgrowth of Salmonellae and the physical property of albumen and vitelline membrane as influenced by egg storage conditions. J. Food Prot., 68, 2553-2558.

Clavijo R.I., Loui C., Andersen G.L., Riley L.W., Lu S., 2006. Identification of genes associated with survival of Salmonella enterica Serovar Enteritidis in chicken egg albumen. Appl. Env. Microbiol., 72, 1055-1064.

Clay C.E., Board R.G., 1991. Growth of Salmonella Enteritidis in artificially contaminated hens' shell eggs. Epidemiol. Infect., 106, 271-281.

Davies R.H., Breslin M., 2003. Investigation of Salmonella contamination and disinfection in farm egg-packing plants. J. Appl. Microbiol., 94, 191-196.

De Buck J., Van Immerseel F., Haesebrouck F., Ducatelle R., 2004. Colonization of the chicken reproductive tract and egg contamination by Salmonella. J. Appl. Microbiol., 97, 233-245.

De Ketelaere B., Bamelis F., Kemps B. Decuypere E., De Baerdemaeker J., 2004. Non-destructive measurements of the egg quality. World's Poult. Sci., 60, 289-302.

De Reu K., Grijspeerdt K., Heyndrickx M., Zoons J., De Baere K., Uyttendaele M., Debevere J., Herman L., 2005. Bacterial eggshell contamination in conventional cages, 
furnished cages and aviary housing systems for laying hens. Brit. Poult. Sci., 46, 149-155.

De Reu K., Grijspeerdt K., Heyndrickx M., Uyttendaele M., Debevere J., Herman L., 2006a. Bacterial shell contamination in the egg collection chains of different housing systems for laying hens. Brit. Poult. Sci., 47, 163-172.

De Reu K., Grijspeerdt K., Messens W., Heyndrickx M., Uyttendaele M., Debevere J., Herman L., 2006b. Eggshell factors influencing eggshell penetration and whole egg contamination by different bacteria, including Salmonella Enteritidis. Int. J. Food Microbiol., 112, 253-260.

Delmas G., Gallay A., Espié E. Haeghebaert S., Pihier N., Weill F.X., De Valk H., Vaillant V., Désenclos J.C., 2006. Les toxiinfections alimentaires collectives en France entre 1996 et 2005. BEH, 51-52, 418-421.

Denis C., Protais J., Corbion B., Picoche B., Colin P., Lahellec C., 1995. Thermorésistance de Salmonella Enteritidis inoculée dans des ovoproduits. Ind. Aliment Agr., Septembre, 659-663.

Doyle M.E., Mazzotta A.S., 2000. Review of studies on the thermal resistance of Salmonellae. J. Food Prot., 63, 779-795.

Doyle M.E., Mazzotta A.S., Wang T., Wiseman D.W., Scott V.N., 2001. Heat resistance of Listeria monocytogenes. J. Food Prot., 64, 410-429.

Duboccage L., Heyndrickx M., Grijspeerdt K., Herman L., 2001. Growth of Salmonella in egg white. Meded Rijksuniv Gent Fak. Landbouwkd Toegep. Biol. Wet., 66, 531-534.

Dunn I.C., Bain M., Edmond A., Wilson P.W., Joseph N., Solomon S., De Ketelaere B., De Baerdemaeker J., Schmutz M., Preisinger R., Waddington D., 2005. Heritability and genetic correlation of measurements derived from acoustic resonance frequency analysis; a novel method of determining eggshell quality in domestic hens. Brit. Poult. Sci., 46, 280-286.

Efsa, 2007. Report of the task force on zoonoses data collection on the analysis of the baseline study on the prevalence of Salmonella in holdings of laying hen flocks of Gallus gallus, The Efsa J., 97.

Efsa, 2009. The community summary report on trends and sources of zoonoses and zoonotic agents in the European Union in 2007. The Efsa J., 223.

Ernst R.A., Fuqua L., 1998. Effect of sweating on shell penetration of Salmonella Enteritidis. J. Appl. Poult. Res., 7, 81-84.

Favier G.L., Escudero M.E., de Guzman A.M., 2001. Effect of chlorine, sodium chloride, trisodium phosphate, and ultraviolet radiation on the reduction of Yersinia enterocolitica and mesophilic aerobic bacteria from eggshell surface. J. Food Prot., 64, 1621-1623.

Foegeding P., Leasor S.B., 1990. Heat resistance and growth of Listeria monocytogenes in liquid whole egg. J. Food Prot., 53, 9-14.

Foegeding P.M., Stanley N.W., 1990. Listeria monocytogenes F5069 thermal death times in liquid whole egg. J. Food Prot., 53, 6-8.

Gantois I., Ducatelle R., Pasmans F., Haesebrouck F., Hautefort I., Thompson A., Hinton J.C., Van Immerseel F., 2006. Butyrate specifically down-regulates Salmonella pathogenicity island 1 gene expression. Appl. Env. Microbiol., 72, 946-949.
Garibaldi J.A., 1970. Role of microbial iron transport compounds in the bacteria spoilage of eggs. Appl. Microbiol., 20, 558-560.

Gast R.K., Beard C.W., 1990. Isolation of Salmonella Enteritidis from internal organs of experimentally infected hens. Avian Dis., 34, 991-993.

Gast R.K., Holt P.S., 2000a. Influence of the level and location of contamination on the multiplication of Salmonella Enteritidis at different storage temperatures in experimentally inoculated eggs. Poult. Sci., 79, 559-563.

Gast R.K., Holt P.S., 2000b. Deposition of phage type 4 and 13a Salmonella Enteritidis strains in the yolk and albumen of eggs laid by experimentally infected hens. Avian Dis., 44, 706-710.

Gast R.K., Holt P.S., 2001. Assessing the frequency and consequences of Salmonella Enteritidis deposition on the egg yolk membrane. Poult. Sci, 80, 997-1002.

Gast R.K., Guard-Petter J., Holt P.S., 2002. Characteristics of Salmonella Enteritidis contamination in eggs after oral, aerosol, and intravenous inoculation of laying hens. Avian Dis., 46, 629-635.

Gast R.K., Holt P.S., Guraya R., 2006. Effect of refrigeration on in vitro penetration of Salmonella Enteritidis through the egg yolk membrane. J. Food Prot., 69, 1426-1429.

Gast R.K., Guraya R., Guard-Bouldin J., Holt P.S., 2007. In vitro penetration of egg yolks by Salmonella Enteritidis and Salmonella Heidelberg strains during thirtysix-hour ambient temperature storage. Poult Sci., 86, 1431-1435.

Gautron J., Hincke M.T., Panheleux M., Garcia-Ruiz J.M., Boldicke T., Nys Y., 2001. Ovotransferrin is a matrix protein of the hen eggshell membranes and basal calcified layer Connect Tissue Res., 42, 255-267.

Gautron J., Réhaut-Godbert S., Jonchère V., Hervé-Crépinet V., Mann K., Nys Y., 2010 L'apport de la génomique fonctionnelle dans l'identification et la caractérisation fonctionnelle des constituants de l'œuf. In : Numéro Spécial Qualité de 1'oeuf. Nys Y. (Ed). Inra Prod. Anim., 23, 133-142.

Gibson G.R., Roberfroid M.B., 1995 Dietary modulation of the human colonic microbiota: introducing the concept of prebiotics. J. Nutr., 125, 1401-1412.

Grijspeerdt K., Kreft J.U., Messens W., 2005. Individual-based modelling of growth and migration of Salmonella Enteritidis in hens eggs. Int. J. Food Microbiol., 100, 323-333.

Guan J., Grenier C., Brooks B.W., 2006. In vitro study of Salmonella Enteritidis and Salmonella typhimurium definitive type 104: survival in egg albumen and penetration through the vitelline membrane. Poult. Sci., 85 , 1678-1681.

Gumudavelli V., Subbiah J., Thippareddi H., Velugoti P.R., Froning G., 2007. Dynamic predictive model for growth of Salmonella Enteritidis in egg yolk. J. Food Sci., 72, M254-M262.

Haines R.B., Morand T., 1940. Porosity of and bacterial invasion through the shell of the hen's egg. J. Hyg., 40, 453-461.

Hincke M.T., Gautron J., Panheleux M. Garcia-Ruiz J., McKee M.D., Nys Y., 2000. Identification and localization of lysozyme as a component of eggshell membranes and eggshell matrix. Matrix Biol., 19, 443-453.
Humphrey T.J., Whitehead A., 1993. Egg age and the growth of Salmonella Enteritidis PT4 in egg contents. Epidemiol. Infect., 111, 209-219.

Humphrey T.J., Chapman PA., Rowe B., Gilbert R.J., 1990. A comparative study of the heat resistance of Salmonella in homogenized whole egg, egg yolk or albumen. Epidemiol. Infect., 104, 237-241.

Huneau-Salaün A., Le Bouquin S., Petetin I., Balaine L., Eono F., 2005. Etude sur la décontamination des élevages de poules pondeuses au sol volet bactériologique. Sci. Techn. Avicoles, 51, 4-11.

Hutchison M.L., Gittins J., Sparks A.W., Humphrey T.J., Burton C., Moore A., 2004. An assessment of the microbiological risks involved with egg washing under commercial conditions. J. Food Prot., 67, 4-11.

Ibrahim H.R., Matsuzaki T., Aoki T., 2001a. Genetic evidence that antibacterial activity of lysozyme is independent of its catalytic function. FEBS Lett., 506, 27-32.

Ibrahim H.R., Thomas U., Pellegrini A., 2001b. A helix-loop-helix peptide at the upper lip of the active site cleft of lysozyme confers potent antimicrobial activity with membrane permeabilization action. J. Biol. Chem., 276, 43767-43774.

Jones D.R., Musgrove M.T., Northcutt J.K, 2004. Variations in external and internal microbial populations in shell eggs during extended storage. J. Food Prot., 67, 2657-2660.

Kang H., Loui C., Clavijo R.I., Riley L.W., Lu S., 2006. Survival characteristics of Salmonella enterica serovar Enteritidis in chicken egg albumen. Epidemiol. Infect., 134, 967-976.

Keller L.H., Benson C.E., Krotec K., Eckroade R.J., 1995. Salmonella Enteritidis colonization of the reproductive tract and forming and freshly laid eggs of chickens. Infect. Immunol., 63, 2443-2449.

Kim J.W., Slavik M.F., 1996. Cetylpyridinium chloride (CPC) treatment on poultry skin to reduce attached Salmonella. J. Food Prot., 59, 322-326.

Knight K.P., Bartlett F.M., McKellar R.C., Harris L.J., 1999. Nisin reduces the thermal resistance of Listeria monocytogenes Scott A in liquid whole egg. J. Food Prot., 62, 999-1003.

Li X, Payne J.B., Santos F.B., Levine J.F., Anderson K.E. ShelcowB., 2007. Salmonella populations and prevalence in layer feces from commercial high-rise houses and characterization of the Salmonella isolates by serotyping antibiotic resistance analysis, and pulsed field gel electrophoresis. Poult Sci., 86, 591-597.

Li Chan E., Shuryo N., 1989. Biochemical basis for the properties of egg white. Biochem. Rev. Poultry Biol., 2, 21-55.

Lock J.L., Board R.G., 1992. Persistence of contamination of hens' egg albumen in vitro with Salmonella serotypes. Epidemiol. Infect., 108, 389-396.

Lorenz F.W., Starr P.B., 1952. Spoilage of washed eggs: effect of sprayed versus static water under different washing conditions. Poult. Sci., 31, 204-213.

Lucore L., Jones F., Anderson K.E., Curtis P.A. 1997. Internal and external bacterial counts from sheells of eggs washed in a commercial-type procesor at various wash-water temperatures. J. Food Prot., 60, 1324-1328. 
Mallet S., Guesdon V., Ahmed A.M.H., Nys Y., 2005. Hygiène des oeufs pondus dans deux modèles de cages aménagées. 6èmes Journ. Rech. Avicole, St-Malo, France, 487-491.

Mallet S., Huneau-Salaün A., Herman L., De Reu K., 2010. Système d'élevage et qualité hygiénique de l'œuf. In: Numéro Spécial Qualité de l'oeuf. Nys Y. (Ed). Inra Prod. Anim., 23, 183-192.

Messens W., Grijspeerdt K., Herman L., 2005. Eggshell characteristics and penetration by Salmonella enterica serovar Enteritidis through the production period of a layer flock. Brit. Poult. Sci., 46, 694-700.

Messens W., Grijspeerdt K., Herman L., 2006. Eggshell penetration of hen's eggs by Salmonella enterica serovar Enteritidis upon various storage conditions. Brit. Poult. Sci., 47, 554-560.

Messens W., Grijspeerdt K., De Reu K., De Ketelaere B., Mertens K., 2007. Eggshell penetration of various types of hens' eggs by Salmonella enterica serovar Enteritidis. J. Food Prot., 70, 623-628.

Michalski C.B., Brackett R.E., Hung Y.C., Ezeike G.O., 2000. Use of capillary tubes and plate heat exchanger to validate U.S Department of Agriculture pasteurization protocols for elimination of Listeria monocytogenes in liquid egg products. J. Food Prot., 63, 921-925.

Miyamoto T., Horie T., Baba E., Sasai K. Fukata T., 1998. Salmonella penetration through eggshell associated with freshness of laid eggs and refrigeration. J. Food Prot., 61, 350-353

Moats W.A., 1980. Classification of bacteria from commercial egg washers and washed and unwashed eggs. Appl. Env. Microbiol., 40, 710-714

Monchois V., Abergel C., Sturgis J., Jeudy S., Claverie J.M., 2001. Escherichia coli ykfE ORFan gene encodes a potent inhibitor of C-type lysozyme. J. Biol. Chem., 276, 18437 18441

Moore J., Madden R.H, 1993. Detection and incidence of Listeria species in blended raw egg. J. Food Prot., 56, 652-654.

Murase T., Holt P.S., Gast R.K., 2005. Growth of Salmonella enterica serovar Enteritidis in albumen and yolk contents of eggs inoculated with this organism onto the vitelline membrane. J. Food Prot., 68, 718721.

Muriana P.M., Hou H., Singh R.K., 1996. A flow-injection system for studying heat inactivation of Listeria monocytogenes and Salmonella Enteritidis in liquid whole egg. J. Food Prot., 2, 121-126.

Musgrove M.T., Jones D.R., Northcutt J.K., Cox N.A., Harrison M.A., 2005. Shell rinse and shell crush methods for the recovery of aerobic microorganisms and enterobacteriaceae from shell eggs. J. Food Prot., 68, 2144-2148

Neilands J.B., 1981. Iron absorption and transport in microorganisms. Ann. Rev. Nutr., 1, 27-46.

Notermans S., Soentoro P.S., Bolder N.M., Mulder R.W., 1991. Adaptation of Listeria in liquid egg containing sucrose resulting in survival and outgrowth. Int. J. Food Microbiol., $13,55-61$.
Okamura M., Miyamoto T., Kamijima Y, Tani H., Sasai K., 2001. Differences in abilities to colonize reproductive organs and to contaminate eggs in intravaginally inoculated hens and in vitro adherences to vaginal explants between Salmonella Enteritidis and other Salmonella serovars. Avian Dis., 45, 962-971.

Palumbo M.S., Beers S.M., Bhaduri S., Palumbo S.A., 1995. Thermal resistance of Salmonella spp. and Listeria monocytogenes in liquid egg yolk and egg yolk products. J. Food Prot., 58, 960-966.

Palumbo M.S., Beers S.M., Bhaduri S., Palumbo S.A., 1996.Thermal resistance of Listeria monocytogenes and Salmonella spp. in liquid egg white. J. Food Prot., 59, 1182-1186.

Protais J., Queguiner S., Boscher E., Piquet J.C., Nagard B., 2003. Effect of housing systems on the bacterial flora of the air. Brit. Poult. Sci., 44, 778-779.

Protais J., Gerault P., Queguiner S., Boscher E, Chidaine B., Ermel G., Rivoal K., Salvat G., Pages J., Thuault D., Huchet V., Coignard M., Bourion F., Federighi M., Jugiau F., Thouveno D. Estathiou T., Lorthioir P., 2006. Identification et comportement des bactéries d'altération dans la matrice oeuf entier liquide. Sci. Techn. Avicoles, 57, 4-13.

Reiber M.A., Conner D.E., Bilgili S.F. 1995. Salmonella colonization and shedding patterns of hens inoculated via semen. Avian Dis., 39, 317-322.

Ruzickova V., 1994. Growth and survival of Salmonella Enteritidis in selected egg foods. Vet. Med., 39, 187-195.

Sadeyen J.R., Trotereau J., Protais J. Beaumont C., Sellier N., 2006. Salmonella carrier-state in hens: study of host resistance by a gene expression approach. Microbes Infect., 8, 1308-1314.

Sahin O., Kobalka P., Zhang Q., 2003. Detection and survival of Campylobacter in chicken eggs. J. Appl. Microbiol., 95, 10701079

Sauveur B., 1988. Structure, composition et valeur nutritionnelle de l'œuf. In : Reproduction des volailles et production d'œufs. INRA Editions, Paris, France, 450p.

Schoeni J.L., Glass K.A., McDermott J.L. Wong AC., 1995. Growth and penetration of Salmonella Enteritidis, Salmonella Heidelber and Salmonella typhimurium in eggs. Int. J. Food Microbiol., 24, 385-396.

Sellier N., Vidal M.L., Baron F., Michel J., Gautron J, 2007. Estimations of repeatability and heritability of egg albumen antimicrobial activity and of lysozyme and ovotransferrin concentration. Brit. Poult. Sci., 48, 559-566.

Shah D.B., Bradshaw J.G., Peeler J.T., 1991. Thermal resistance of egg, associated epidemic strains of Salmonella Enteritidis. J. Food Sci., 56, 391-393.

Shivaprasad H.L., Timoney J.F., Morales S., Lucio B., Baker R.C., 1990. Pathogenesis of Salmonella Enteritidis infection in laying chickens. Studies on egg transmission, clinica signs, fecal shedding, and serologic responses. Avian Dis., 34, 548-557.

Stevens L., 1991. Mini-review, egg white proteins. Comp. Biochem. Physiol., 100B, 1-9.

Susuki S., 1994. Pathogenicity of Salmonella Enteritidis in poultry. Int. J. Food Microbiol., 21, 89-105.
Swayne D.E., Beck J.R., 2004. Heat inactivation of avian influenza and Newcastle disease viruses in egg products. Avian Pathol., $33,512-518$

Tayeb I.T., Nehme P.A., Jaber L.S., Barbour E.K., 2007. Competitive exclusion against Salmonella Enteritidis in layer chickens by yoghurt microbiota : impact on egg production, protection and yolk-antibody and cholesterol levels. J. Appl. Microbiol., 102, 1330-1336.

Thormar H., Hilmarsson H., Bergsson G., 2006. Stable concentrated emulsions of the 1-monoglyceride of capric acid (monocaprin) with microbicidal activities against the foodborne bacteria Campylobacter jejuni, Salmonella spp., and Escherichia coli. Appl. Env. Microbiol., 72, 522-526.

Tranter H.S., Board R.G., 1984. The influence of incubation temperature and $\mathrm{pH}$ on the antimicrobial properties of hen egg albumen. J. Appl. Bacteriol., 56, 53-61.

Tung M.A., Garland M.R., Gill P.K., 1979. A scanning electron microscope study of bacterial invasion in hen's egg shell. J. Inst. Can. Sci. Technol. Aliment., 12 16-22.

Vadehra D.V., Baker R.C., Naylor H.B., 1970. Role of cuticule in spoilage of chicken eggs. J. Food Sci., 35, 5-6.

Van der Wielen P.W., Lipman L.J., van Knapen F., Biesterveld S., 2002. Competitive exclusion of Salmonella enterica serovar Enteritidis by Lactobacillus crispatus and Clostridium lactatifermentans in a sequencing fed-batch culture. Appl. Env. Microbiol., 68, 555-559.

Van Immerseel F., De Buck J., Pasmans F., Bohez L., Boyen F., Haesebrouck F., Ducatelle R., 2004. Intermittent long-term shedding and induction of carrier birds after infection of chickens early posthatch with a low or high dose of Salmonella enteritidis. Poult. Sci., 83, 1911-1916.

Vidal M.L., Baron F., Ahmed A., Michel J., Sellier N., 2003. Genetic variability in the antimicrobial activity of hen egg white. Brit. Poult. Sci., 44, 791-792.

Vollmer W., 2008. Structural variation in the glycan strands of bacterial peptidoglycan. FEMS Microbiol. Rev., 32, 287-306.

Wales A., Breslin M., Carter B., Sayers R., Davies R., 2007. A longitudinal study of environmental Salmonella contamination in caged and free-range layer flocks. Avian Pathol., 36, 187-197.

Wang C., Shelef L.A., 1991. Factors contributing to antilisterial effects of raw egg albumen. J. Food Sci., 56, 1251-1254.

Wang H., Slavik M.F., 1998. Bacterial penetration into eggs washed with various chemicals and stored at different temperatures and times. J. Food Prot., 61, 276-279.

Wigley P., Berchieri A., Page K.L., Smith A.L., Barrow P.A., 2001. Salmonella enterica serovar Pullorum persists in splenic macrophages and in the reproductive tract during persistent, disease-free carriage in chickens. Infect. Immunol., 69, 7873-7879.

Wigley P., Hulme S.D., Powers C., Beal R.K., Berchieri A., 2005. Infection of the reproductive tract and eggs with Salmonella enterica serovar Pullorum in the chicken is associated with suppression of cellular immunity at sexual maturity. Infect. Immunol., 73 , 2986-2990. 


\title{
Résumé
}

Le risque de contamination par les microorganismes, et notamment par Salmonella, est une préoccupation majeure de la filière œufs et ovoproduits.

Le contenu des œufs provenant d'élevages sains est en général stérile mais il peut toutefois être contaminé par une flore diversifiée contenant des microorganismes d'altération et parfois pathogènes. L'œuf dispose cependant d'un arsenal remarquable de défenses destinées à préserver l'embryon de toute invasion microbienne au cours de son développement. Cet article fait le point sur l'origine des contaminations de l'œuf et les mécanismes de défense antimicrobienne. Les mesures permettant de limiter la présence et le développement des microorganismes dans l'œuf sont discutées, au niveau de l'élevage, du stockage et du conditionnement.

Le cassage entraîne systématiquement la contamination du blanc et du jaune par contact avec les coquilles souillées, conduisant ainsi à des ovoproduits très périssables. De nombreux microorganismes peuvent ainsi contaminer les ovoproduits. La maîtrise de leur qualité microbiologique est un impératif, en particulier lorsqu'ils sont intégrés dans des aliments crus ou peu cuits. Les moyens de mâ̂trise sont discutés et plus particulièrement le respect des bonnes pratiques d'hygiène et la maîtrise des procédés de stabilisation. L'importance de la maîtrise des températures pour le contrôle des microorganismes pathogènes et d'altération, dans les ovoproduits et dans les œufs, est particulièrement soulignée.

\begin{abstract}
Microbiology of egg and egg products

The risk of contamination by microorganisms, and mostly by Salmonella, is a major concern in the sectors of egg production and egg product manufacturing. Under healthy breeding conditions, the egg content is generally sterile. However, it can be contaminated by a diversified microbiota containing food spoilage microorganisms and sometimes pathogenic bacteria. The egg has however remarkable self-defence properties intended to preserve the embryo of any microbial invasion during its development. This article gives a progress report on the origin of egg contamination and on egg's antimicrobial defence mechanisms. The means to limit the presence and the development of microorganisms in eggs are discussed, at the egg production level, and during egg storage and conditioning. Egg breaking systematically involves the contamination of egg white and egg yolk through contact with the spoiled shells, thus giving rise to highly perishable egg products. The control of their microbiological quality is required, in particular when they are integrated in raw or undercooked food. The means of control are discussed and particularly the respect of good hygiene practices and relevant stabilization processes. The significance of monitoring temperatures for the control of pathogenic and food spoilage microorganisms is particularly underlined.
\end{abstract}

BARON F., JAN S., 2010. Microbiologie de l'œuf et des ovoproduits. In : Numéro Spécial, Qualité de l'œuf. Nys Y. (Ed). Inra Prod. Anim., 23, 193-204. 
